\title{
Bio-efficacy of microbial infused rice straw compost on plant growth promotion and induction of disease resistance in chili
}

\begin{abstract}
Microbial fortified organic amendment in chili cultivation may affect plant development and disease suppression. Microbial infused rice straw compost, commercial rice straw compost, and fungicide Benomyl for chili (Capsicum annum L.) cultivation and control of Sclerotium foot rot were studied under glass house condition. Chili seed cv. Kulai were sown in the Sclerotium rolfsii infested and non-infested soil. After two weeks, five healthy seedlings were transplanted into planting bags. Growth performance and development of disease symptoms associated with S. rolfsii foot rot infection were assessed. Applying microbial infused rice straw compost increased seed germination and plant growth, and suppressed development of foot rot compared to using commercial rice straw compost and the Benomyl. A higher disease reduction $(84.6 \%$ ) occurred with $15 \mathrm{Mg} \cdot$ ha-1 microbial infused rice straw compost (62.7\%), followed by Benomyl (53.8\%), and $15 \mathrm{Mg} \cdot$ ha-1 commercial rice straw compost (46.2\%). Application of microbial infused rice straw compost at $15 \mathrm{Mg} \cdot$ ha-1 yielded optimum seed germination and seedling establishment, plant growth, and disease suppression. Microbial infused rice straw compost is a good alternative to chemical fungicide in controlling Sclerotial disease in chili.
\end{abstract}

Keyword: Microbial infused rice straw; Chili; Plant development; Disease suppression 